\title{
Cells as factories for humanized encapsulation
}

Zhengwei Mao, Regis Cartier, Anja Hohl, Maura Farinacci, Anca Dorhoi, Tich-Lam Nguyen, Paul Mulvaney, John Ralston, Stefan H. E. Kaufmann, Helmuth Möhwald, and Dayang Wang

\section{Supporting Materials}

\section{Experimental Details}

\section{Using live cells to produce CMCs}

1.1. Cell culture. Human embryonic kidney cells (HEK293) were maintained in Dulbecco's Modified Eagles Medium (DMEM, Gibco) supplemented with 100U/mL penicillin, $100 \mu \mathrm{g} / \mathrm{mL}$ gentamicin and $10 \%$ fetal calf serum (FCS, Gibco). Mouse fibroblasts (3T3) were maintained in DMEM supplemented with $200 \mu \mathrm{g} / \mathrm{mL}$ glutamine, $100 \mathrm{U} / \mathrm{mL}$ penicillin, 100 $\mu \mathrm{g} / \mathrm{mL}$ gentamicin and $10 \% \mathrm{FCS}$. The cells were incubated at $37{ }^{\circ} \mathrm{C}$ in a humidified atmosphere containing $5 \% \mathrm{CO}_{2}$ and used at $90 \%$ confluence.

1.2. $\mathrm{CMC}$ production. To produce $\mathrm{CMCs}$, cells were cultured in a $25 \mathrm{~cm}^{2}$ flask until $90 \%$ confluence, washed twice with PBS, and then incubated in $2 \mathrm{~mL}$ serum-free DMEM containing $10 \mu \mathrm{g} / \mathrm{mL}$ Cytochalasin B (CB, Sigma, $1 \mathrm{mg} / \mathrm{mL}$ stock solution in Dimethyl sulfoxide) for $30 \mathrm{~min}$ at $37^{\circ} \mathrm{C}$. Then, the cells and formed capsules were detached by $0.05 \%$ trypsin and $0.01 \%$ EDTA. The cell/capsules suspensions were vigorously shaken for $30 \mathrm{~s}$ and were mixed with the same volume of FCS to a final FCS concentration of $50 \%$. The mixture was centrifuge twice at $500 \mathrm{rpm}$ for $10 \mathrm{~min}$ to remove cells. The supernatant was centrifuge again at $2000 \mathrm{rpm}$ for $15 \mathrm{~min}$ to collect the CMCs. The CMCs were re-dispersed in PBS containing $50 \% \mathrm{FCS}$ (PBS/50\% FCS), washed three times, and stored in PBS/50\% FCS with gentle shaking for later use. 
To produce CMCs stained with carboxyfluorescein diacetate (cFDA) or carboxyfluorescein succinimidyl ester (CFDA-SE, Sigma), cells were incubated in normal culture medium containing $20 \mu \mathrm{g} / \mathrm{mL}$ cFDA or cFDA-SE for $24 \mathrm{~h}$ prior to CMC production. cFDA-SE directly reacted with the amino groups on proteins in the cells, thus leading to stable fluorescent labeling. Then, the cells were washed twice with PBS and incubated in CB solution to produce CMCs according to the aforementioned protocol.

1.3. Characterization. CMCs were incubated in $10 \mu \mathrm{g} / \mathrm{mL} \mathrm{cFDA}(1 \mathrm{mg} / \mathrm{mL}$ stock solution in acetone) and $10 \mu \mathrm{g} / \mathrm{mL}$ solution of NBD-PE, 1,2-diphytanoyl-sn-glycerol -3phosphoethanolamine-N-(7-nitro-2-1,3-benzoxadiazol-4-yl) (ammonium salt) in PBS to stain the cytoplasm and cell membrane, respectively. The CMCs were washed twice with the aid of 15 min centrifugation at $2000 \mathrm{rpm}$, visualized and counted on a Leica DM IRBE confocal laser scanning microscope (CLSM).

\section{Study of loading of small molecules into CMCs and their controlled release out of}

the CMCs. To load with amphiphilic rhodamine $6 \mathrm{G}$, cells cultured in a $25 \mathrm{~cm}^{2}$ flask were incubated in $2 \mathrm{~mL}$ DMEM containing $1 \mathrm{mg} / \mathrm{mL}$ rhodamine $6 \mathrm{G}$ for $30 \mathrm{~min}$ at $37^{\circ} \mathrm{C}$. The cells were washed twice with PBS and incubated in CB solution to produce CMCs according to the aforementioned protocol.

To load hydrophilic carboxyfluorescein and calcein, firstly, cells were incubated with their hydrophobic precursors, carboxyfluorescein diacetate (cFDA) and calcein acetoxymethyl ester (Calcein AM) $(1 \mathrm{mg} / \mathrm{mL}$ stock solution in acetone), at the concentration of $20 \mu \mathrm{g} / \mathrm{mL}$ in DMEM, respectively. After incubation at $37^{\circ} \mathrm{C}$ for $30 \mathrm{~min}$, cells were washed twice with $\mathrm{PBS}$ and incubated in $\mathrm{CB}$ solution to produce $\mathrm{CMCs}$ according to the aforementioned protocol. 
To study the release kinetics of the molecules encapsulated with them, CMCs were dispersed in tris buffer in the presence and absence of $10 \mathrm{mM}$ adenosine-triphosphate (ATP) at $37{ }^{\circ} \mathrm{C}\left(\sim 10^{7} \mathrm{CMCs}\right.$ per $\left.\mathrm{mL}\right)$. Note that since the phosphate ions in PBS significantly affect the ATP activity, tris buffer was used instead of PBS for this study. After a certain incubation time, the CMCs were separated by centrifugation at $2000 \mathrm{rpm}$ for $15 \mathrm{~min}$. $500 \mu \mathrm{L}$ of the supernatant was taken out whilst $500 \mu \mathrm{L}$ of the buffer were supplemented to maintain the total volume constant at $1 \mathrm{~mL}$. The fluorescence intensity of released molecules was measured using a fluoromax - 4 spectrofluorometer. The release amounts of the encapsulated molecules were integrated and the molecule concentrations were determined from the calibration curves of different molecules.

\section{Loading nanoparticles into CMCs}

3.1. Fluorescent nananoparticle synthesis. Oil soluble, octadecylamine (ODA) stabilized, CdSe/CdCdS/ZnS/ZnS/ZnS/ZnS core-shell quantum dots (CdSe@ZnS QDs) (CdSe@ODA QDs), and water soluble, CdSe@ZnS QDs stabilized by poly(styrene-co-maleic anhydride, derivatized with Jeffamine-M-1000 polyetheramine on the outmost surface (PEGylated CdSe QDs), were synthesized according to the literature. ${ }^{1,2} 14 \mathrm{~nm}$ gold nanoparticles (NPs) with rhodamine conjugated poly(oligo(ethylene glycol) methyl methacrylate) (OEGMA) brushes anchored on their surfaces were prepared via ligand exchange, according to previous references. ${ }^{3}$ The sizes of the NPs were obtained via dynamic light scattering, performed on a Malvern zetasizer, and the fluorescence spectra of the NPs were obtained on a fluoromax - 4 spectrofluorometer .

3.2. NP loading into CMCs. To load NPs, cells were cultured to $90 \%$ confluence in 25 $\mathrm{cm}^{2}$ flasks and incubated with cell culture medium containing $50 \mu \mathrm{g} / \mathrm{mL}$ PEGylated CdSe QDs 
or $2 \mathrm{mg} / \mathrm{mL}$ PEGylated gold NPs and $100 \mu \mathrm{M}$ chloroquine at $37^{\circ} \mathrm{C}$. After $4 \mathrm{~h}$, the cells were washed by PBS twice and then incubated in CB solution to produce CMCs according to the aforementioned protocol. The fluorescence spectra of the dispersions of NP-loaded CMCs in PBS ( $10^{7}$ CMCs per $\mathrm{mL}$ ) were obtained using a fluoromax- 4 spectrofluorometer and the loading amount of NPs were estimated from the fluorescence intensity according to the calibration curves of different NPs.

\section{Study of CMC macrophages internalization assay.}

4.1. Preparation of QD-loaded PLGA particles. 30mg PLGA (generously donated by Boehringer Ingelheim Pharma GmbH \& Co. KG, Germany, and containing 10 wt \% PEG) and $0.3 \mathrm{mg}$ CdS@ODA QDs were dissolved in $1 \mathrm{~mL}$ chloroform. The chloroform solution of the PLGA/QD mixtures were emulsified at $4^{\circ} \mathrm{C}$ in $5 \mathrm{~mL}$ water containing $3 \mathrm{wt} \%$ aqueous solution of poly(vinyl alcohol) (80\% hydrolyzed, Sigma-Aldrich) via ultrasonication for $30 \mathrm{~s}$. The emulsions were stirred gently at room temperature to harden for $4 \mathrm{~h}$, followed by desiccation for $1 \mathrm{~h}$ under vacuum to remove any residual chloroform. The QD-loaded PLGA particles were centrifuged at $5000 \mathrm{rpm}$ for $20 \mathrm{~min}$ at $4{ }^{\circ} \mathrm{C}$ and then washed three times with double distilled water to remove excess of PVA in the dispersion media, leading PVAstabilized PLGA particles.

4.2. Preparation of NBD-PE labeled lipid vesicles. $7 \mathrm{mg}$ 1,2-dimyristoyl-sn-glycero-3phosphor-choline (DMPC), 3 mg 1,2-dioleoyl-sn- glycerol-3- phosphocholine (DOPC) and 0.1 mg NBD-PE were mixed together and dissolved in $1 \mathrm{~mL}$ chloroform, and rotary-dried in a small round-bottom flask to form a lipid cake. After completely dried overnight under vacuum, the lipid cake was hydrated in $1 \mathrm{~mL}$ PBS containing $1 \mathrm{mg} / \mathrm{mL}$ sucrose for $30 \mathrm{~min}$ at $37^{\circ} \mathrm{C}$. Uniform lipid vesicles were formed by ultrasonic for $10 \mathrm{~s}$, followed by extrusion with 1 
$\mu \mathrm{m}$ membranes (Avanti) at $37^{\circ} \mathrm{C}$.

4.3. Preparation of Fc-modified CMCs. CMCs were washed twice with PBS and incubated in $2 \mathrm{~mL}$ PBS solution of EZ-link Sulfo-NHS-Biotin $(1 \mathrm{mg} / \mathrm{mL}$, Thermo scientific) at 37 ${ }^{\circ} \mathrm{C}$ for $30 \mathrm{~min}$. After washing twice with PBS, the biotinized CMCs were incubated in $\mathrm{PBS} / 50 \% \mathrm{FCS}$ and $50 \mu \mathrm{g} / \mathrm{mL}$ FITC conjugated anti-biotin IgG-Fc (Dianova) for $1 \mathrm{~h}$ at $37^{\circ} \mathrm{C}$, leading to the Fc-modifed surfaces (Fc-CMCs).

4.4. Cytotoxicity test. THP-1 macrophages (approximately $5 \times 10^{4}$ ), i. e. human acute monocytic leukemia cell line, were seeded into each well of 96-well plates and differentiated in RPMI-1640 medium (Sigma) containing $10 \%$ FCS and $50 \mathrm{ng} / \mathrm{mL}$ phorbol myristate acetate (PMA, Sigma). THP-1 macrophages were incubated with CMCs at a CMC-to-macrophase ratio of $15: 1$ at $37^{\circ} \mathrm{C}$ in the presence of $5 \% \mathrm{CO}_{2}$ for $1 \mathrm{~h}$ and 1 day, respectively. After incubation, the cell monolayers were washed twice with PBS and the cells were then incubated in $100 \mu \mathrm{L}$ of RPMI/10\%FCS medium containing $100 \mu \mathrm{g} / \mathrm{mL}$ MTT (3-(4,5)-dimethylthiahiazo (-z-y1)-3,5di- phenytetrazoliumromide, Sigma) at $37^{\circ} \mathrm{C}$ in the presence of $5 \% \mathrm{CO}_{2}$ for $1.5 \mathrm{~h}$. After plates were centrifuged at $500 \mathrm{rpm}$ for $3 \mathrm{~min}$, following by decanting the supernatants, $200 \mu \mathrm{L}$ dimethyl sulfoxide (Sigma) was added into each well of the plates. After vigorous shaking of the plates, the optical density at $490 \mathrm{~nm}$ was measured at an automatic plate reader. Data from MTT studies were analyzed using ANOVA; the significant level was set as $p<0.05{ }^{4}$

4.5. Macrophage internalization assay. THP-1 macrophages (approximately $2.5 \times 10^{5}$ ) were seeded into each well of 24 well plates and differentiated in RPMI-1640 medium containing $10 \%$ FCS and $50 \mathrm{ng} / \mathrm{mL}$ PMA. The macrophages were incubated with $\mathrm{CMCs}$ loaded with PEGylated CdSe QDs or gold NPs or stained with CFDA-SE, Fc-CMCs, PLGA particles loaded with CdSe@ODA QDs, or NBD-PE labeled lipid vesicles at a capsule (or particle)-to-macrophage ratio of $15: 1$ at $37^{\circ} \mathrm{C}$ in the presence of $5 \% \mathrm{CO}_{2}$ for $1 \mathrm{~h}$ and 1 day, 
respectively. After their monolayers were washed twice by PBS, the macrophages were detached and washed using PBS containing 0.5\% trypsin. To distinguish between dead and living cells, $1 \mu \mathrm{g} / \mathrm{mL}$ PBS solution of propidium iodide (PI, Sigma) was added before the flow cytometry measurement. Flow cytometry was performed on a FACScan cytometer (BD, Bioscience) according to the manufacturer's protocols. Macrophages were gated using forward scatter (FSC) and side scatter (SSC) of an only CMC control to exclude contaminating free CMCs from the final analysis. All the results were reproduced in three separate experiments.

\section{References:}

1. Lees, E.E. et al. Experimental determination of quantum dot size distributions, ligand packing densities, and bioconjugation using" Analytical Ultracentrifugation, Nano lett. 8, 2883 (2008).

2. Lees, E.E. et al., The preparation of colloidally stable, water-soluble, biocompatible, semiconductor nanocrystals with a small hydrodynamic diameter, ACS Nano 3, 1121 (2009).

3. Edwards, E. W., Chanana M., Wang D. Capping gold nanoparticles with stimuli-responsive polymers to cross water-oil interfaces: in-depth insight to the trans-interfacial activity of nanoparticles. J. Phys. Chem. C 112, 15207-15219 (2008).

4. Fisher, R.A. (1956), Statistical Methods and Scientific Inference. New York: Hafner 
Figure S1. Formation and characterization of genesis of CMCs from 3T3 fibroblasts. (a) Left panel: Fluorescence CLSM image of adherent 3T3 cells with the cytoplasm stained by carboxyfluorescein. Right pannle: Fluorescence CLSM image of 3T3 cells obtained in several minutes after addition of $\mathrm{CB}$. It indicates the shrinkage of the cells and the formation of round capsules containing the cytoplasm stained by carboxyfluorescein. (b) Left panel: High magnification fluorescence CLSM image of CMCs derived from 3T3 cells. Right panel: overlay of high magnification fluorescence and transmission CLSM images of the CMCs. (c) Fluorescence CLSM image of a CMC with the cell membrane stained by NBD-PE, showing a green fluorescent shell. (d) Histogram of the size distributions of the resulting CMCs. More than $70 \%$ of the CMCs are $0.5-2 \mu \mathrm{m}$ in diameter. 

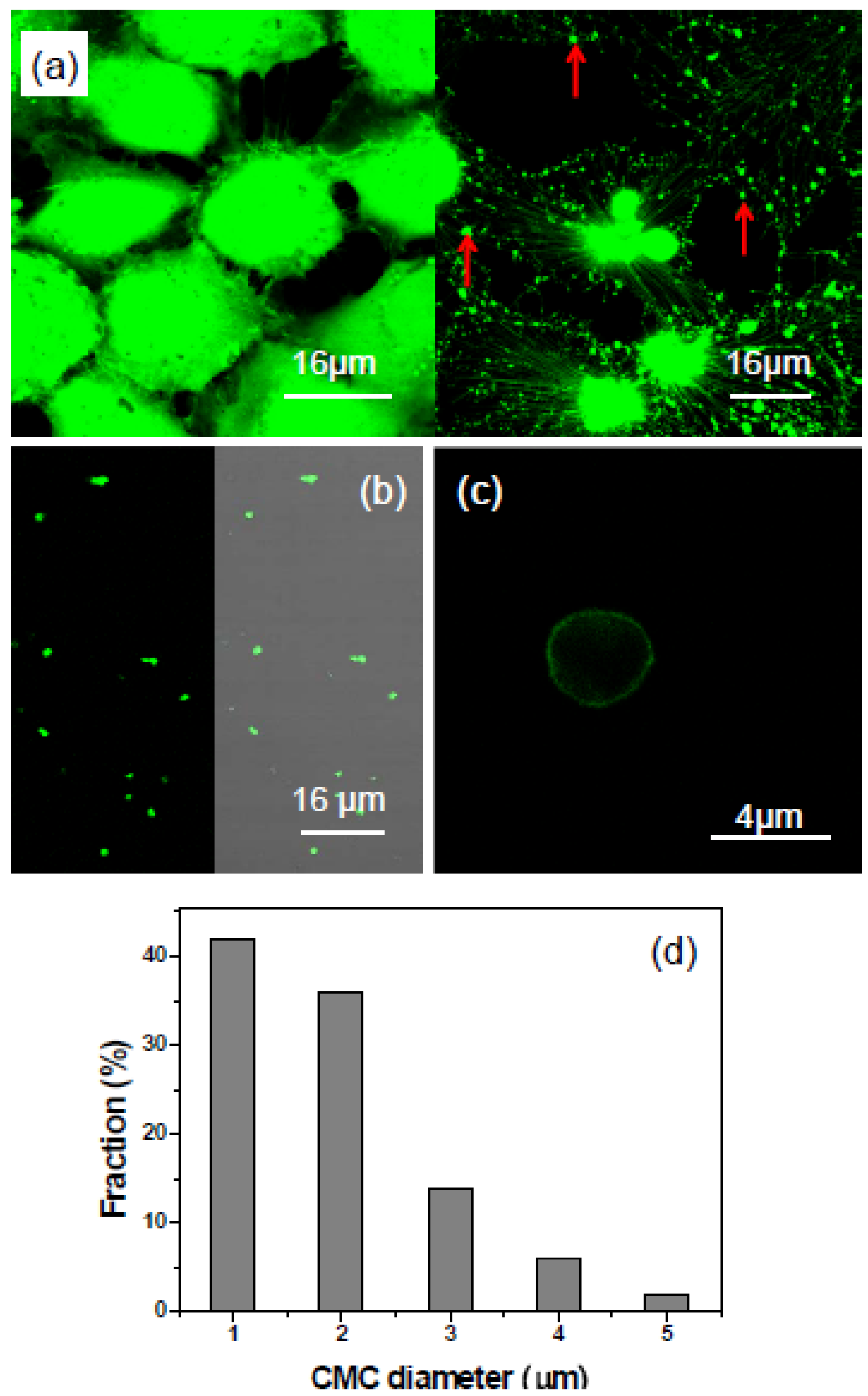
Figure S2. Histograms of the fractions of individual CMCs derived from HEK293 (a) and 3T3 cells (b) versus the incubation times in PBS (black columns) and PBS/50\%FCS (red columns). (c) Fluorescence CLSM image of aggregates of HEK 293-CMCs, obtained after $8 \mathrm{~h}$ incubation in PBS (left panel) and the overlay with fluorescence and transmission CLSM image (right panel).
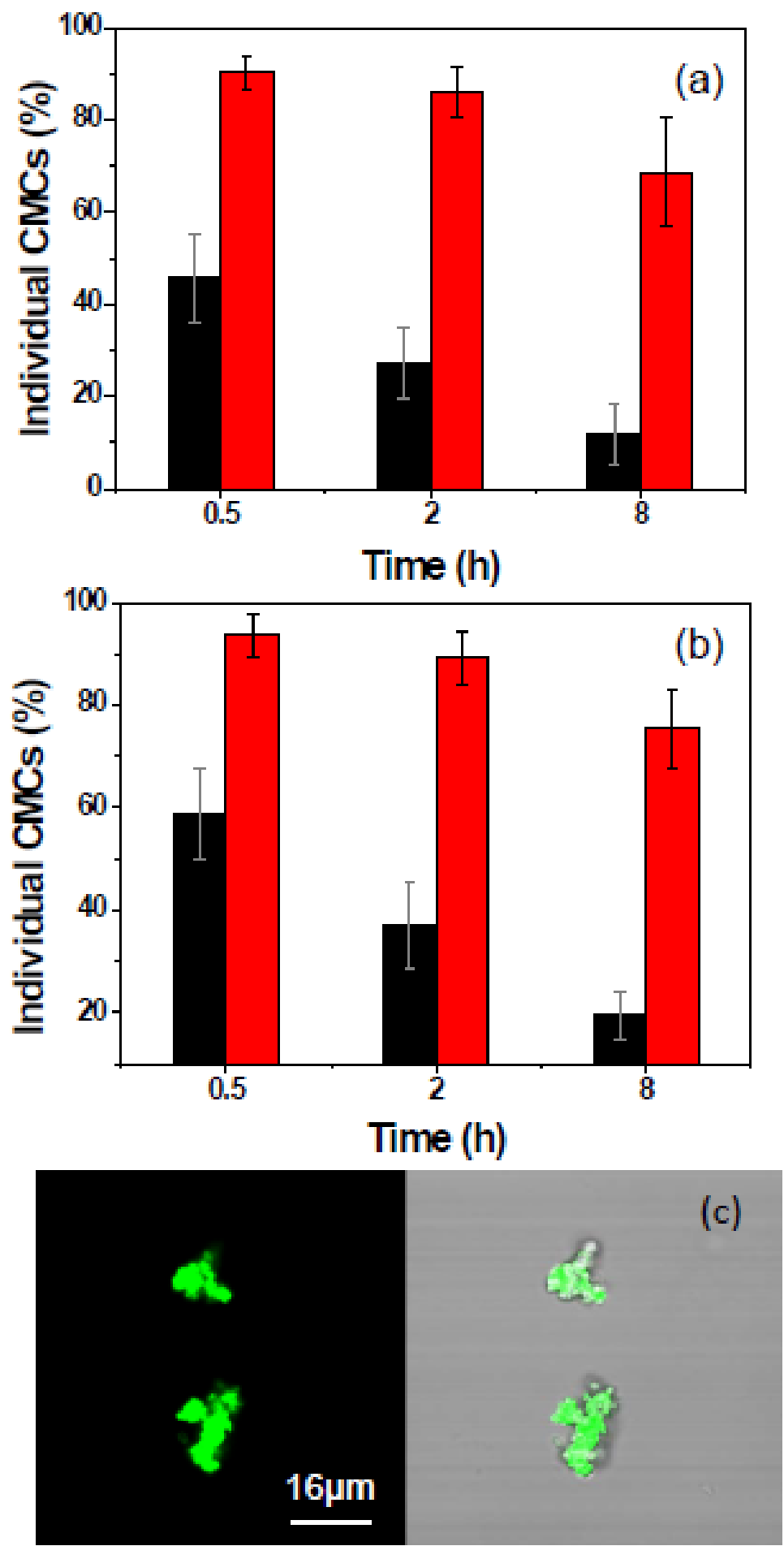
Figure S3. Plots of the accumulative release of rhodamine $6 \mathrm{G}$ and carboxyfluorescein from CMCs derived from $3 T 3$ cells versus incubation time.

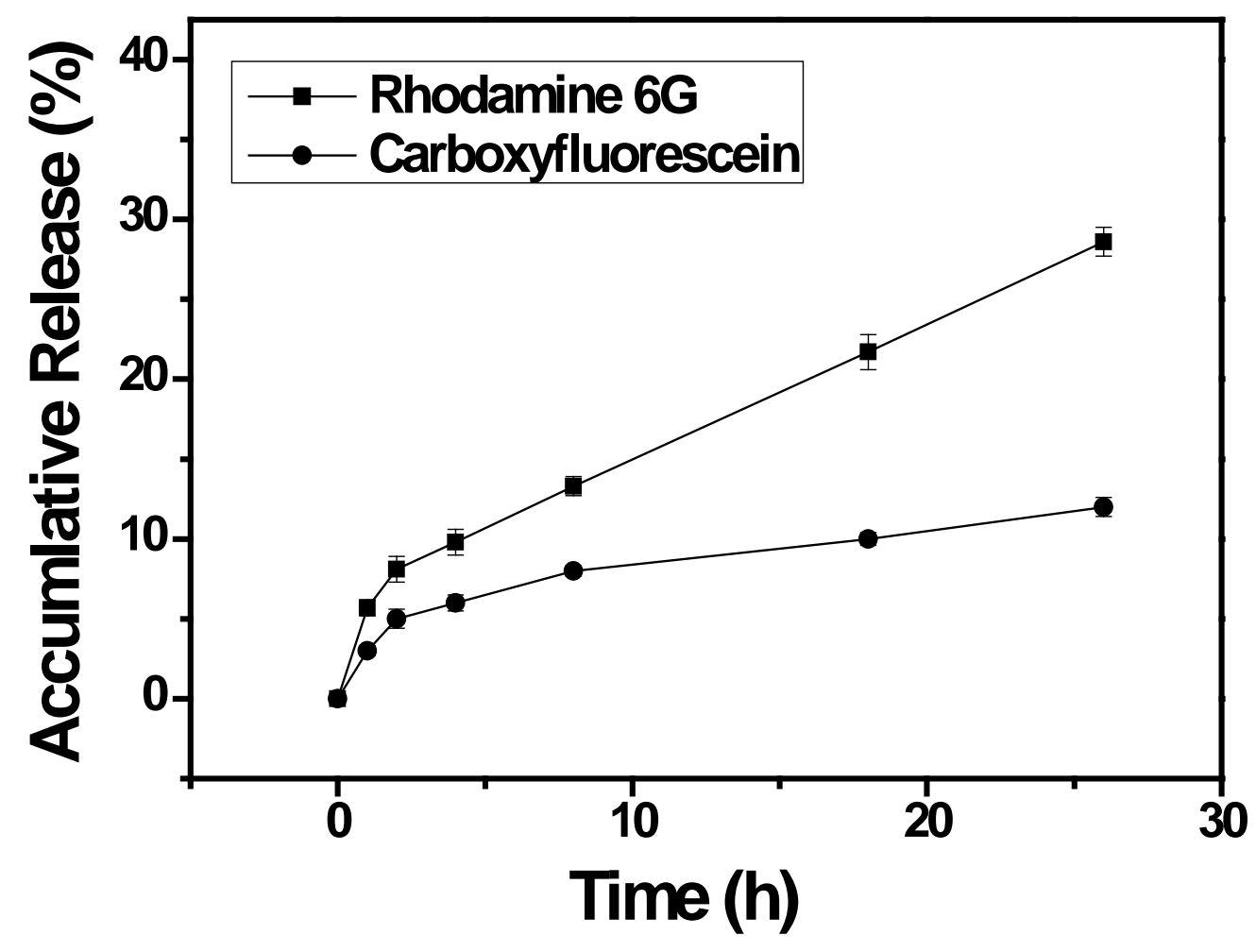


Figure S4. Fluorescence spectra of aqueous dispersion of PEGylated CdSe QDs with sizes of $5.3 \mathrm{~nm}(\mathrm{a})$ and $5.9 \mathrm{~nm}(\mathrm{~b})$. The insets show the optical photos of these aqueous dispersions in the absence and present of UV irradiation.
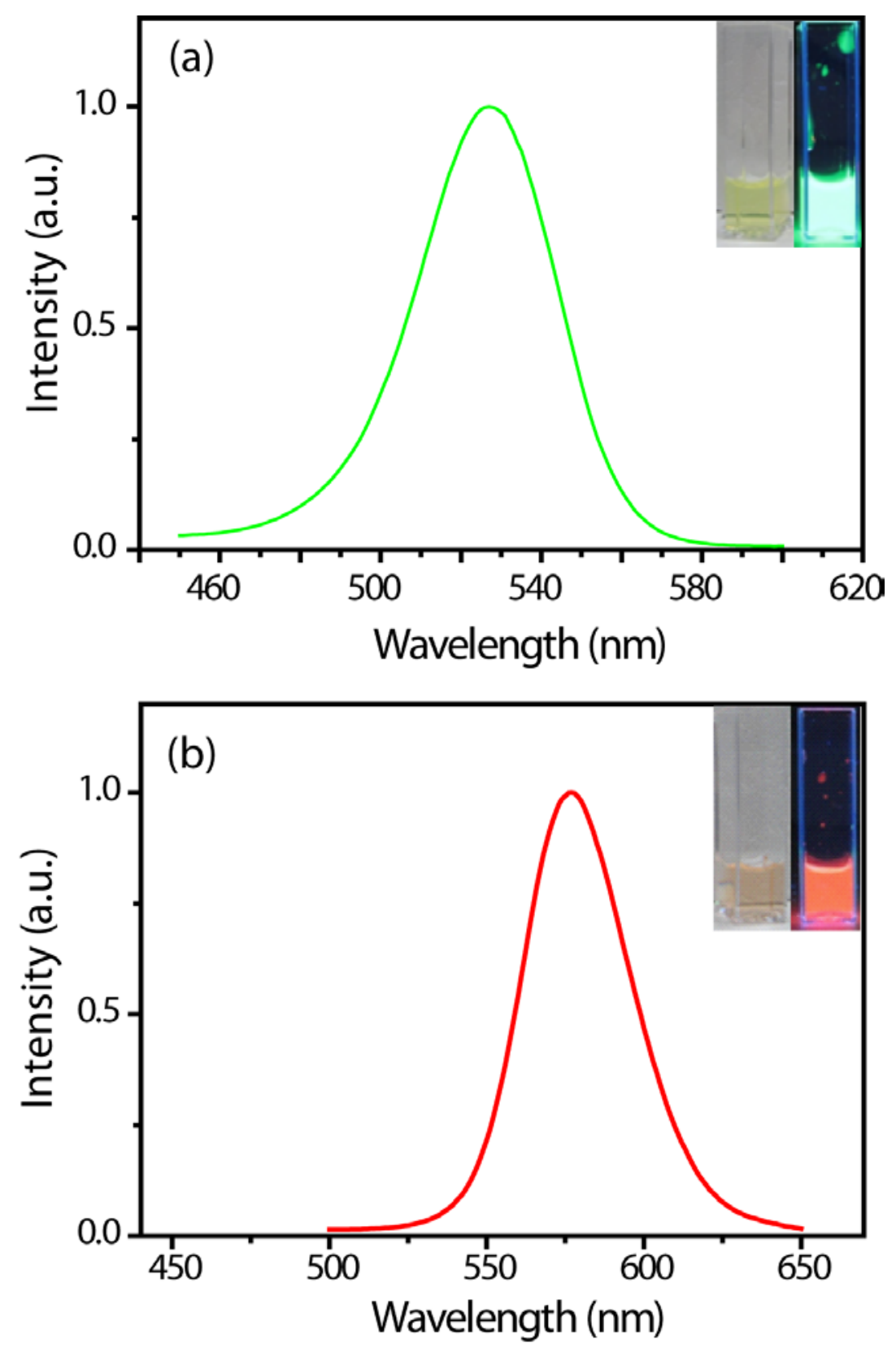
Figure S5. Fluorescence CLSM image (left) and fluorescence/transmission overlay of 3T3 cells incubated with PEGylated CdSe QDs with sizes of $5.3 \mathrm{~nm}$ for $4 \mathrm{~h}$ at 37 으 $\mathrm{C}$ in the absence (a) and presence of $100 \mu \mathrm{M}$ chloroquine (b).
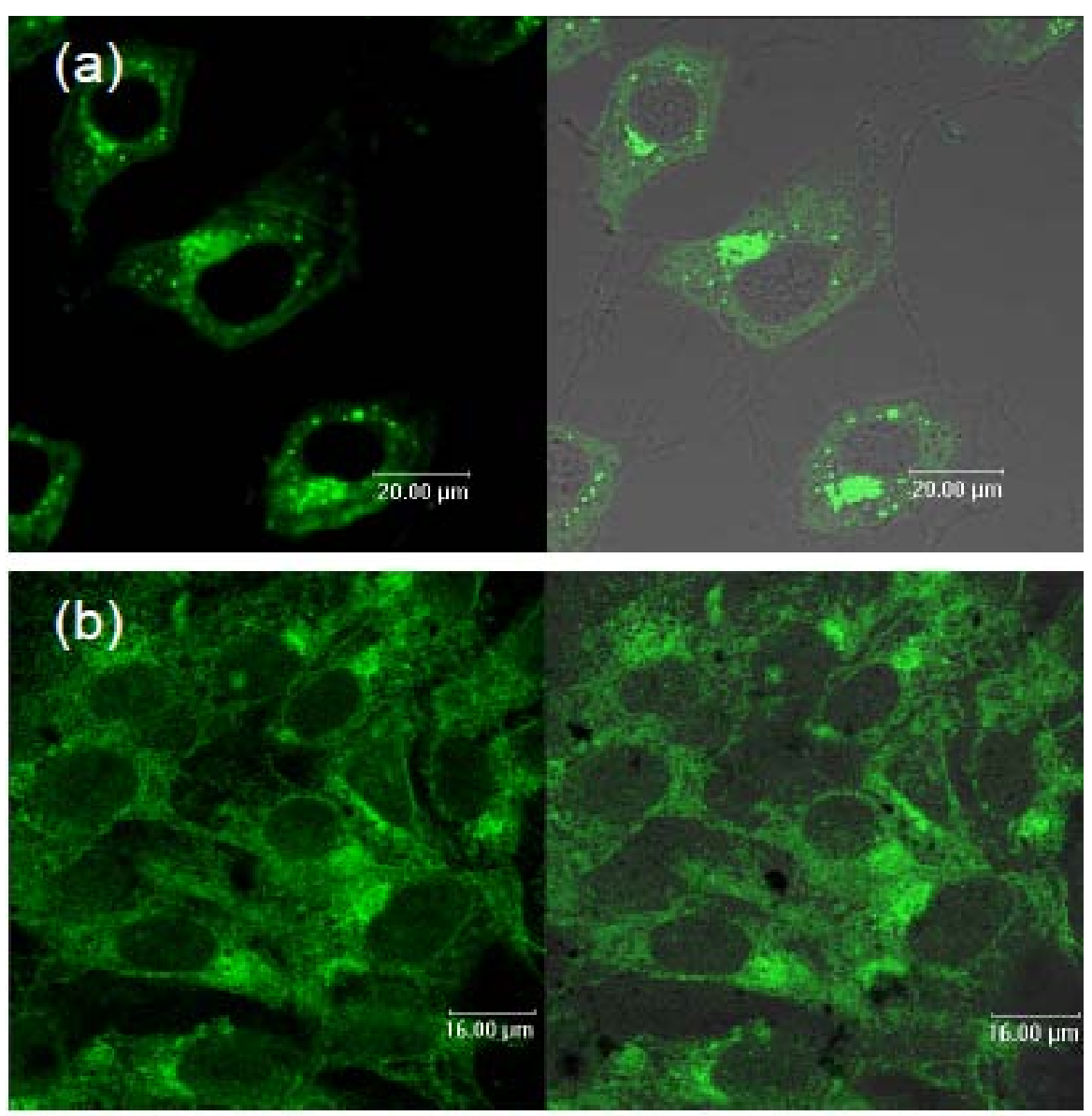
Figure S6. Fluorescence CLSM image (left) and fluorescence/transmission overlay of 3T3 cells incubated with PEGylated CdSe QDs with sizes of $5.9 \mathrm{~nm}$ for $4 \mathrm{~h}$ at 37 으 in the absence (a) and presence of $100 \mu \mathrm{M}$ chloroquine (b).
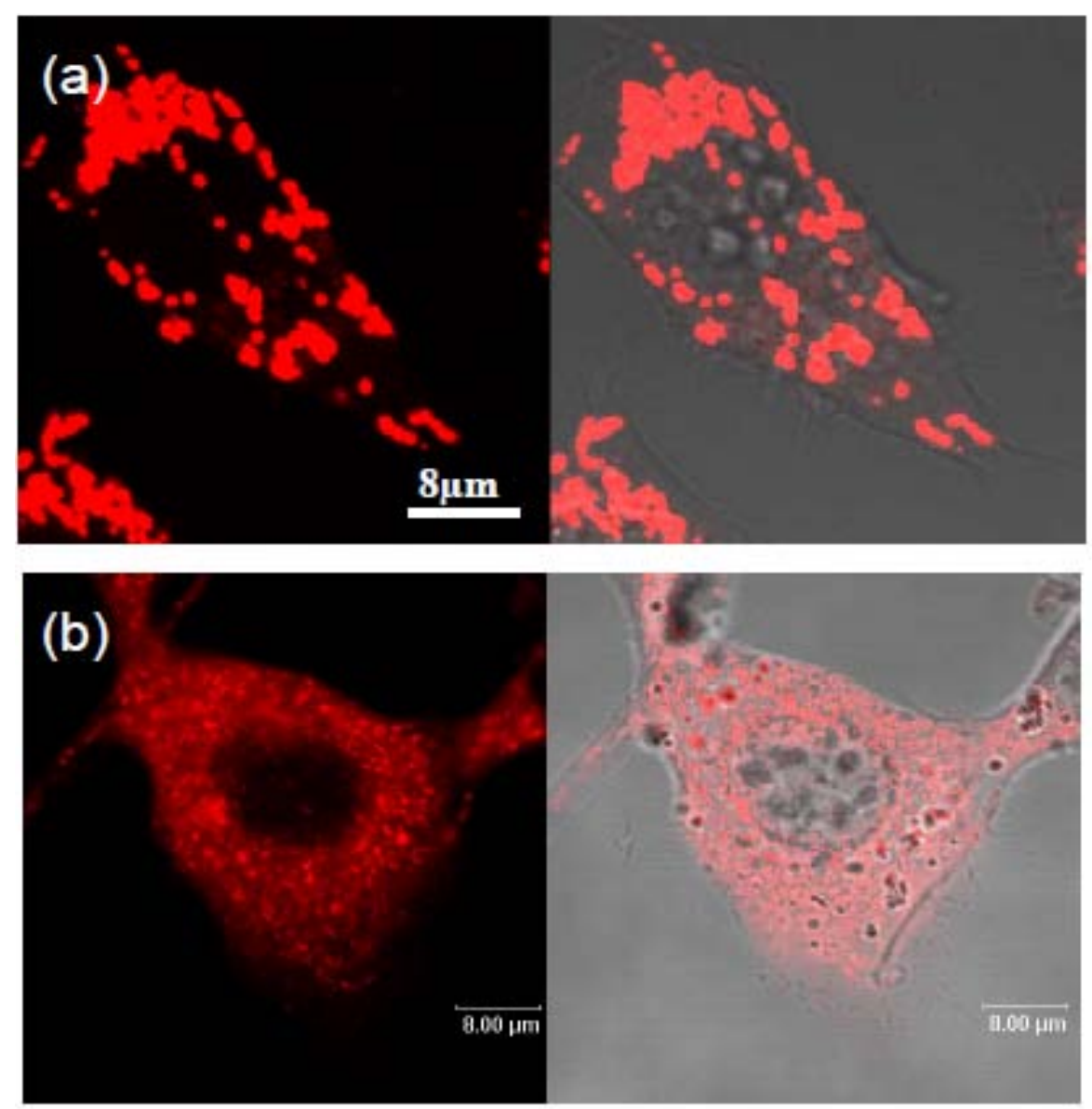
Figure S7. (a) Fluorescence CLSM image (left) and fluorescence/transmission overlay of 3T3 cells incubated with PEGylated gold NPs with sizes of $14 \mathrm{~nm}$ for $4 \mathrm{~h}$ at $37 \mathrm{o} C$ in the presence of $100 \mu \mathrm{M}$ chloroquine. (b) Fluorescence CLSM image (left) and fluorescence/transmission overlay of CMCs derived from 3 T3 cells, in which $14 \mathrm{~nm}$ PEGylated gold NPs are encapsulated. The polymer brushes anchored on the gold NPs were labeled by rhodamine. The high magnification images are shown in the insets.
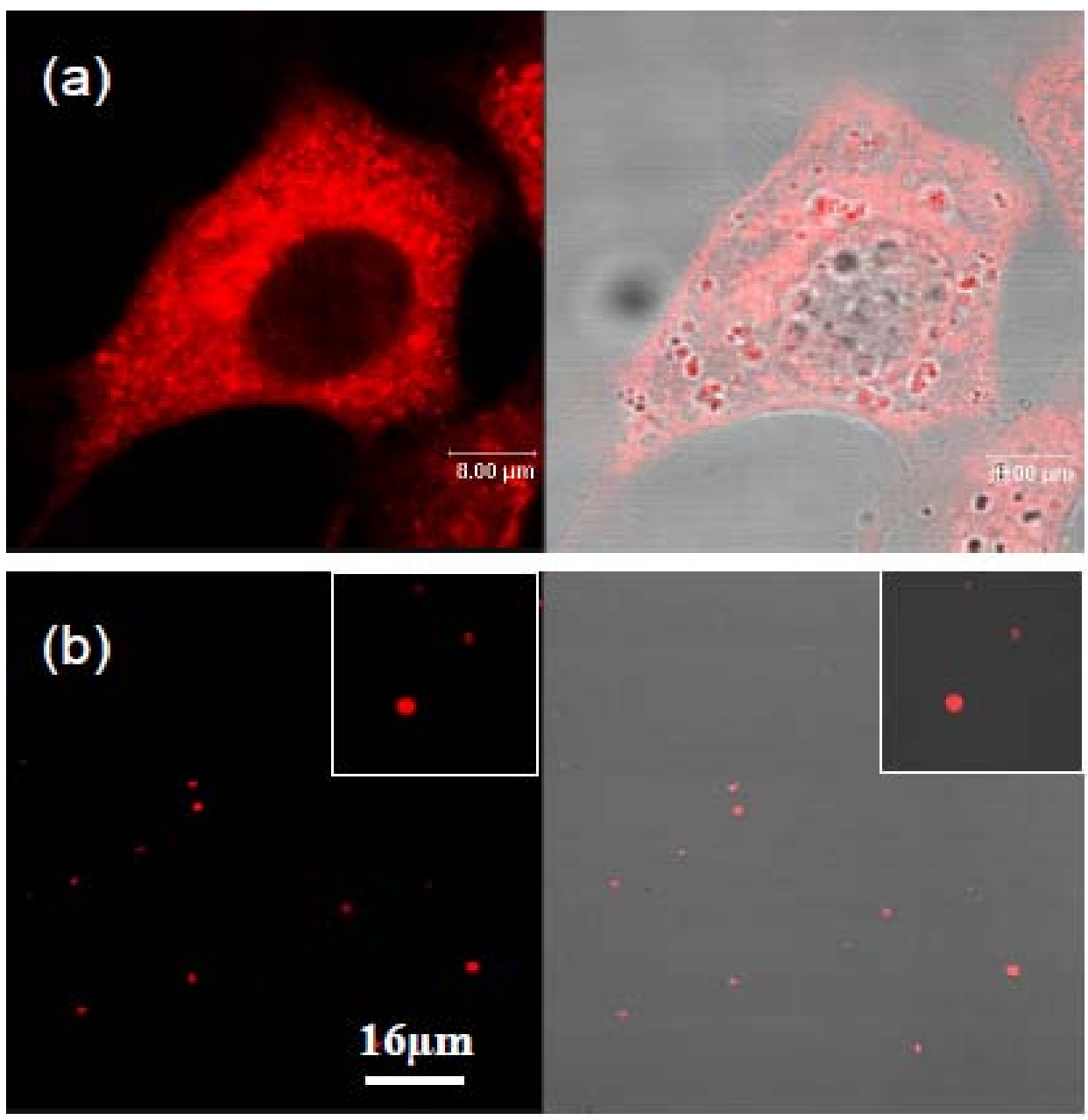
Figure S8 The Fluorescence CLSM image (left) and fluorescence/transmission overlay of CMCs derived from HEK 293 cells, in which $5.3 \mathrm{~nm}$ (a) and $5.9 \mathrm{~nm}$ PEGylated CdSe QDs and 14 nm PEGylated gold NPs (c) are encapsulated.
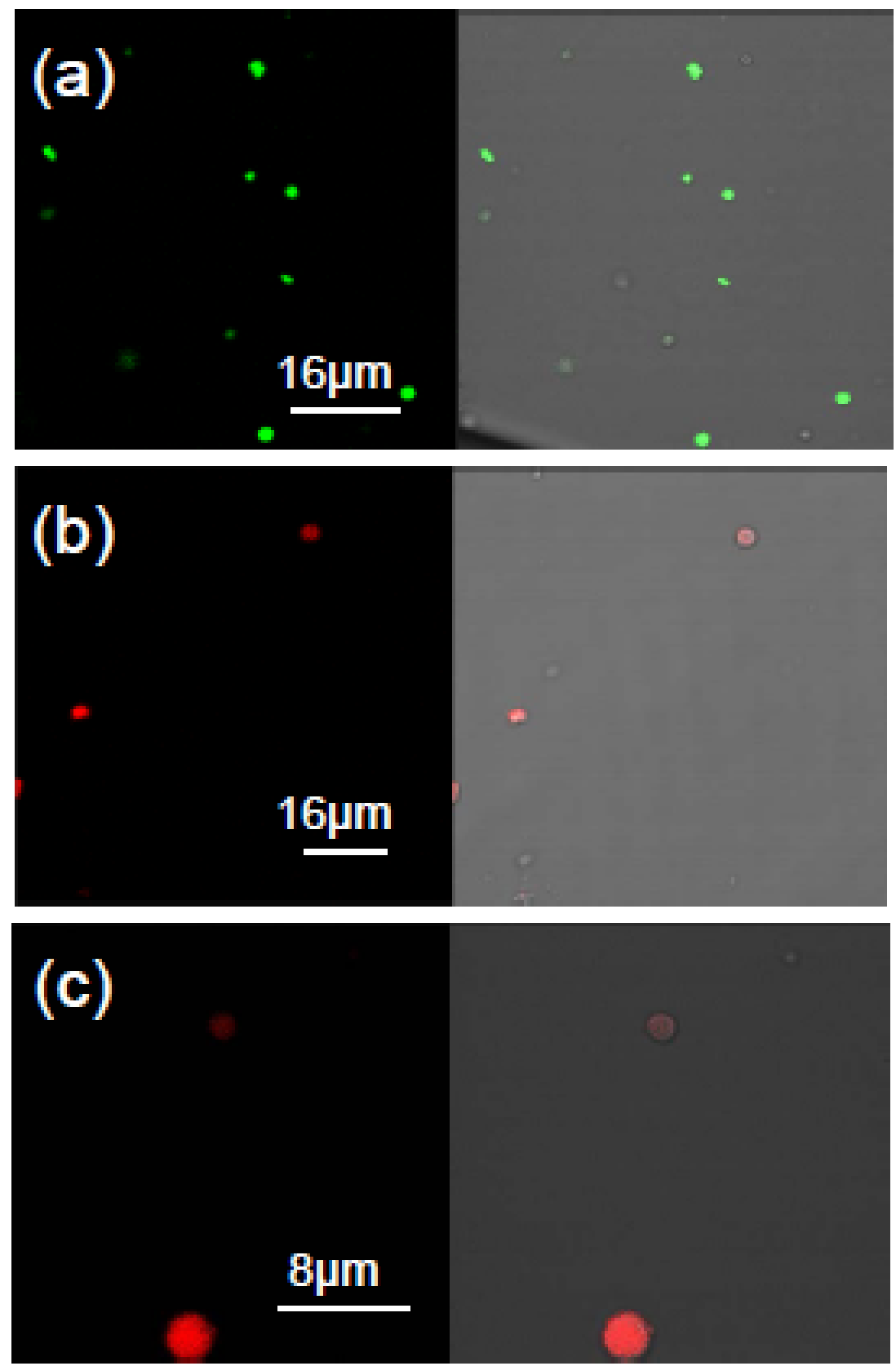
Figure S9. THP-1 macrophages' viability based on the MTT method after $1 \mathrm{~h}$ and 1 day incubation with CMCs. The CMC-to-macrophages ratio is $15: 1$. The results indicated that the CMCs did not have obvious cytotoxicity at given concentration. The viability of the cells incubated with different CMCs are not significantly changed compared with the CMC free control; the significant level $(p)$ is smaller than 0.05 .

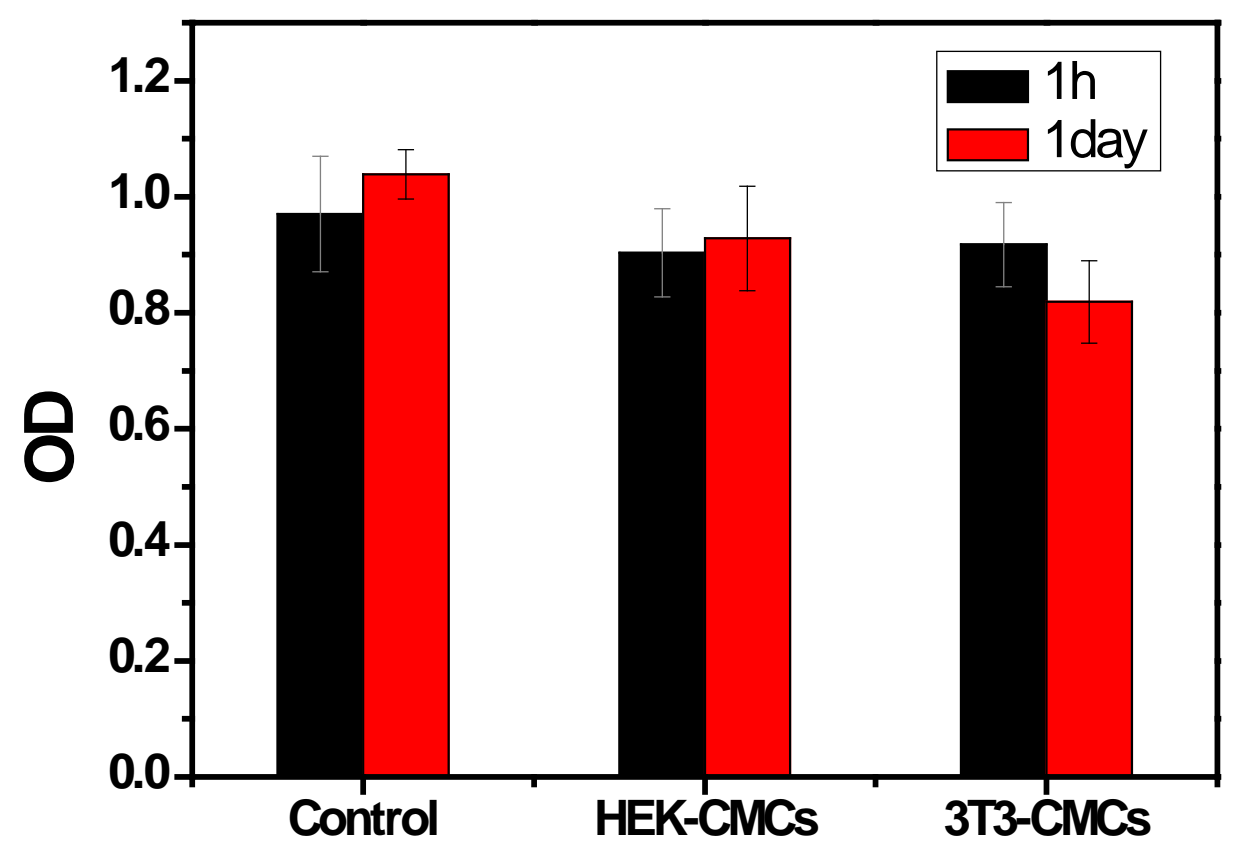


Figure 10. Size distribution profiles of PLGA particles loaded with CdSe@ODA QDs (a) and lipid vesicles labeled by NBD-PE (b) in PBS. The results have been obtained by DLS.
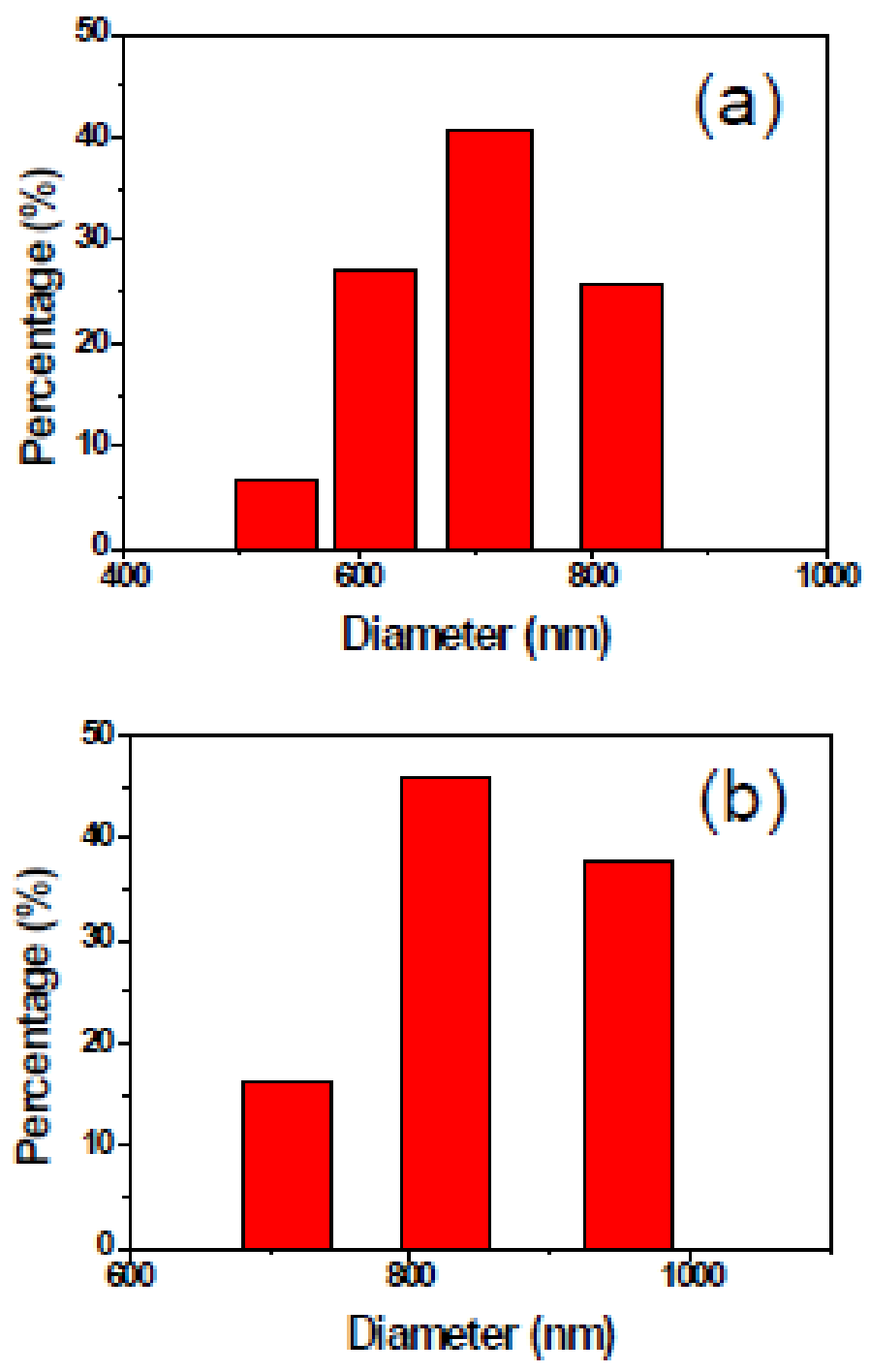
Figure 11. Histogram of fractions of fluorescence-positive THP-1 macrophages after incubation with NBD-PE labeled lipid vesicles, CMCs loaded with PEGylated CdSe QDs, and Fc-CMCs loaded with PEGylated CdSe QDs for $1 \mathrm{~h}$ (upper panel) and 1 day (low panel)
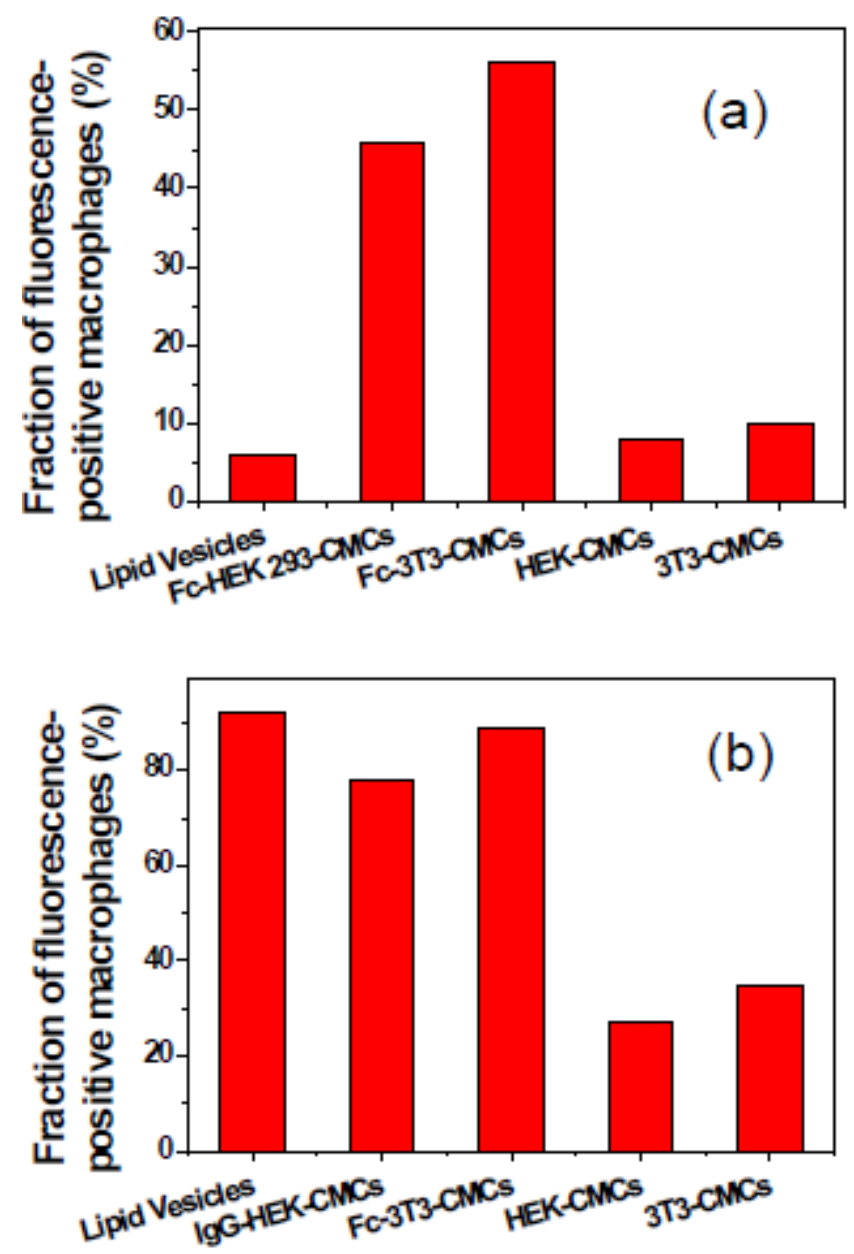
Figure S12. Fluorescence CLSM images of Fc-CMCs derived from HEK 293 (a) and 3T3 (b) cells.

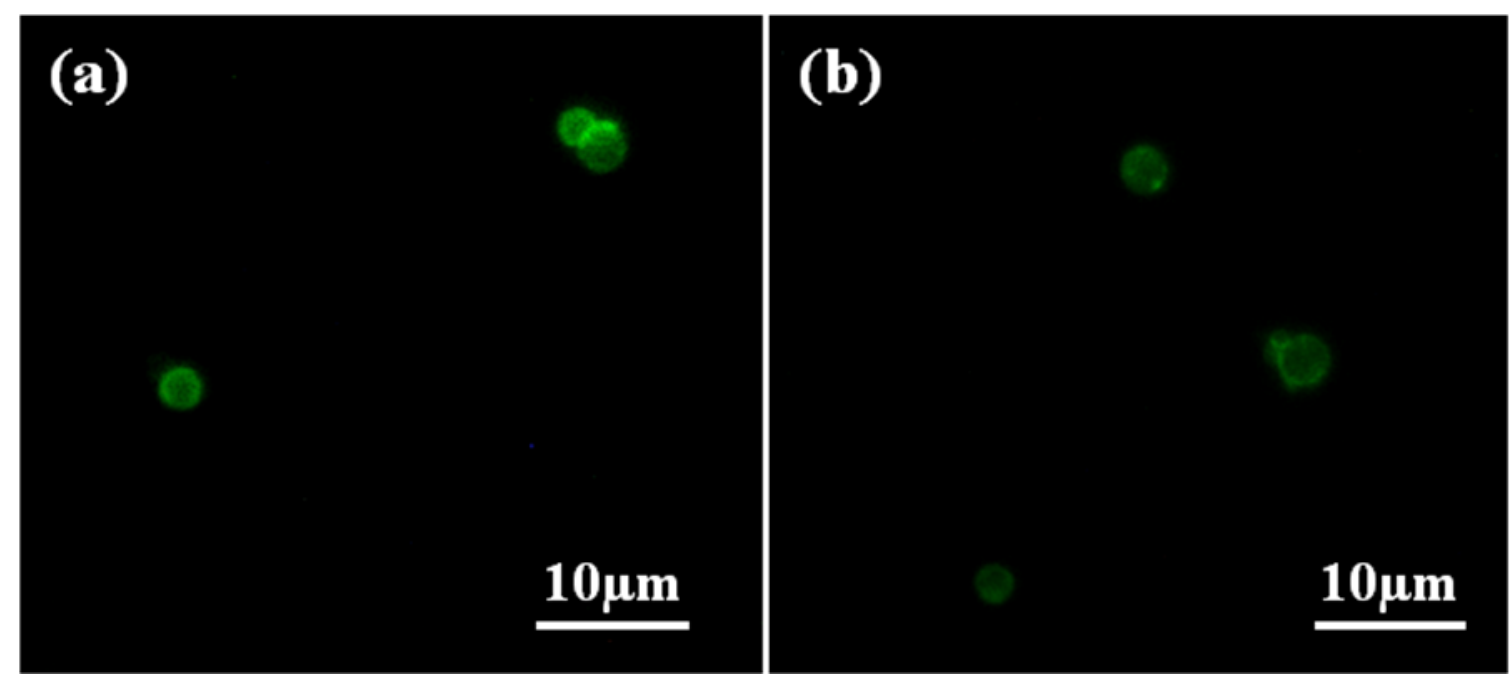

